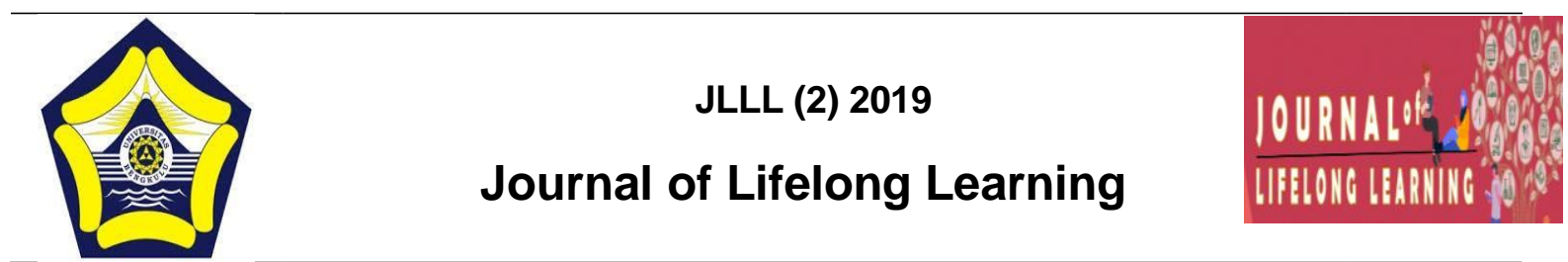

\title{
UPAYA TENAGA PENDIDIK DALAM MENINGKATKAN MOTIVASU PESERTA DIDIK DALAM MENGHAFAL AL-QUR'AN
}

\author{
Diana Azizah ${ }^{1}$, Ilham ${ }^{2}$, Parlan ${ }^{3}$ \\ ${ }^{1}$ Nonformal Education, University of Bengkulu, Indonesia, dinaazizah29@gmail.com \\ ${ }^{2}$ Nonformal Education, University of Bengkulu, Indonesia, ilhamadbullah418@gmail.com \\ ${ }^{3}$ Nonformal Education, University of Bengkulu, Indonesia, parlanunib@gmail.com
}

\begin{abstract}
The purpose of this research in general is to described about how students motivation in memorization al-quran at Bakti Ilaahi Tahfidz House bengkulu city. Methods used in this study was a qualitative methodology a data collection, using a technique interview observation and documentation. Based on the research the conclusions may be drawn that first, santri motivation in memorization quran varies and tending to less stable, this is santri age young 12-15 need assistance and the year guidance so reminded santri tight to individual motivation can so stable and the purpose of learning can be achieved easily. Second, educators have tried to in full to increase the motivation is to submit those, a gift, competition, knowing the outcome, a compliment, punishment and attract. But we cannot deny that the motivation to learn consists of two which is intrinsic motivation or intrinsic and motivation from the outside namely, extrinsic motivation intrinsic motivation is much better than the extrinsic motivation because intrinsic motivation comes from individuals santri alone or awareness of the students own. Third, factors that give rise to motivate students is a factor intrinsic and extrinsic but more dominant derived from extrinsic factor at the sight of motivation santri unstable santri will cheer on when given the recognition and punishment by educators and motivation santri will increase third educators provides guidance motivation that contains about memorizing the quran and fishing for the growing intrinsic motivation in himself students..
\end{abstract}

Keywords :Motivation, Students, Memorizing the Al-quran, Tahfidz House

\section{(C) 2019 Dept of Nonformal Education UNIB}

Address correspondence:

e-ISSN

JI. W.R. Supratman, Kandang Limun, Muara Bangka Hulu,

Kota Bengkulu, Bengkulu 38371 


\section{PENDAHULUAN}

Ditengah krisis akhlak yang melanda generasi muda dewasa ini Rumah Tahfidz Bakti Ilaahi menjadi salah satu wadah lembaga pendidikan non formal untuk membentengi generasi muda dari pengaruh negatif dari globalisasi dan moderenisasi. Berdiri pada tanggal 12 Januari 2016 dibawah Yayasan Al-Fida Rumah Tahfidz Bakri Ilaahi memiliki tujuan mulia yaitu untuk membina generasi muda yang memiliki keinginan untuk menghafal quran. Sebagai satu-satunya tepat menghafal quran untuk usia SMP di Kota Bengkulu Rumah Tahfidz Bakti Ilaahi hadir untuk memenuhi kebutuhan masyarakat akan sebuah lembaga pendidikan quran yang berkualitas serta fokus membina hafalan qur'an 30 juz. Rumah Tahfidz Bakti Ilaahi diharapkan dapat mencetak generasi muda penghafal qur'an yang berkualitas, menjadi kebanggaan umat islam dan dapat mengamalkan ilmunya di tengah masyarakat baik itu bengkulu maupun masyarakat luas.

Motivasi adalah komponen penting dalam tercapainya tujuan pembelajaran terlebih dalam menghafal qur'an yang dapat dikatakan bukan hal yang mudah. Oleh karenanya motivasi

menjadi fokus penting untuk ditingkatkan dalam proses pembelajaran. Tinggi rendahnya motivasi peserta didik dipengaruhi oleh faktor intrinsik atau faktor yang berasal dari individu sendiri dan faktor ekstrinsik. Dilihat dari latar belakang masalah maka permasalahan yang diangkat dalam penelitian ini adalah 1) bagaimana motivasi peserta didik dalam menghafal alquran di Rumah Tahfidz Bakti Ilaahi Kota Bengkulu?, 2) bagaimana upaya tenaga pendidik dalam menghafal al-qyran di Rumah Tahfidz Bakti Ilaahi Kota Bengkulu, 3) faktor apa saja yang mempengaruhi motivasi peserta didik dalam menghafal al-quran di Rumah Tahfidz Bakti Ilaahi Kota Bengkulu.

\section{METODE}

Dalam penelitian ini sasaran yag dicapai dalam penelitian kualitatif diarahkan pada upaya menemukan teori-teori yang bersifat deskriptif. Peneliti menggunakan tipe deskriptif karena peneliti mencoba menggambarkan secara mendalam tentang motivasi peserta didik dalam menghafal qur'an Di Rumah Tahfidz Bakti Ilaahi Kota Bengkulu. Pada penelitian ini peneliti akan melaksanakan wawancara, observasi dan dokumentasi terhadap subjek penelitian untuk memperoleh data yang akurat.

\section{HASIL DAN PEMBAHASAN}

Berdasarkan hasil wawancara, observasi dan dokumentasi adapun hasil analisis data mengenai motivasi peserta didik dalam menghafal al-quran di Rumah Tahfidz Bakti Ilaahi Kota Bengkulu, sebagai berikut:

1. Pertama, motivasi peserta didik atau santri di Rumah Tahfidz Bakti Ilaahi Kota Bengkulu sangat bervariasi dan tidak stabil. Kurangnya kesadaran diri individu untuk bergerak menghafal ataupun bertanya ketika menghadapi kesulitan sehingga tujuan yang diharapkan sulit tercapai. Kenadati demikian hal ini tidak dapat terlepas dari pengaruh usia santri yang dapat dikatakan masih anak-anak yaitu usia 12-15 tahun sehingga emosi masih labil dan memerlukan pengawasan serta bimbingan yang berkelanjutan.

2. Tenaga pendidik telah berupaya secara maksimal untuk meningkatkan motivasi santri yaitu dengan memberikan angka, hadiah, saingan/kompetisi, mengetahui hasil, pujian, hukuman dan menarik minat santri. Namun tidak dapat kita pungkiri bahwa motivasi belajar terdiri 
atas dua yaitu motivasi dari dalam atau intrinsik dan motivasi dari luar yaitu motivasi ekstrinsik, motivasi intrinsik jauh lebih baik dari pada motivasi ekstrinsik karena motivasi intrinsik berasal dari individu santri sendiri atau kesadaran santri sendiri sehingga motivasi ekstrinsik hanya sebagai penunjang motivasi intrinsik begitu pula yang telah dilakukan oleh tenaga pendidik hanya berupa dorongan dari luar berupaya untuk menumbuhkan motivasi intrinsik santri dengan cara memberikan bimbingan motivasi sesering mungkin agar motivasi santri tetap terjaga.

3. Faktor yang menimbulkan motivasi santri adalah faktor intrinsik maupun ekstrinsik namun lebih dominan berasal dari faktor ekstrinsik karena melihat dari motivasi santri yang tidak stabil santri akan semangat pada saat diberikan penghargaan dan hukuman oleh tenaga pendidik dan motivasi santri akan mningkat ketiga tenaga pendidik memberikan bimbingan motivasi yang berisi tentang hal-hal yang berkaitan dengan menghafal quran dan memancing agar tumbuhnya motivasi intrinsik dalam diri peserta didik, karena motivasi intrinsik juga dapat timbul karena dorongan dari orang lain berupa pengetahuan dan pengalaman.

\section{PENUTUP}

Dari hasill penelitian di lapangan tentang Motivasi Santri dalam Menghafal Quran di Rumah Tahfidz Bakti Ilaahi Kota Bengkulu, berdasarkan masalah, tujuan penelitian, hasil penelitian, dan pembahasan maka dapat disimpulkan bahwa, Pertama, motivasi peserta didik atau santri di Rumah Tahfidz Bakti Ilaahi Kota Bengkulu sangat bervariasi. Kurangnya kesadaran diri individu untuk bergerak menghafal ataupun bertanya ketika menghadapi kesulitan sehingga tujuan yang diharapkan sulit tercapai. Kedua, untuk meningkatkan motivasi santri dalam menghafal quran, guru sudah berupaya dengan berbagai macam upaya . Ketiga, banyak faktor yang mempengaruhi motivasi santri dalam menghafal quran baik motivasi intrinsik maupun ekstrinsik. Faktor intrinsik yaitu faktor-faktor yang berasal dari dalam individu santri berupa tujuan, orientasi dan cita-cita santri di masa depan yang berkaitan dengan menghafal. Faktor ekstrinsik yaitu faktor yang berasal dari luar atau faktor yang dirangsang oleh orang diluar individu seperti hukuman dan penghargaan yang diberikan oleh tenaga pendidik dan orang tua, sarana dan pasarana untuk menunjang proses menghafal quran yang lengkap, program dan kegiatan yang menarik seperti ekstrakulikuler dan rekreasi serta kekondusifan lingkungan yang dapat mempengaruhi kenyamanan dan kondisi santri dalam proses menghafal Qur’an. 


\section{REFERENSI}

Al-Kaheel, Abduldaem. 2015. Negeri-Negeri Penghafal Al-quran. Jakarta:Tarbawi Press.

Abdul Aziz. Abdul Rauf. 2004. Kiat Sukses Menjadi Hafidz Qur'an Daiyah: Sarat Dengan Penanaman Motivasi, Penjelasan Teknis dan Memecahkan. Bandung: Syamil Cipta Media.

Ahsin W, Al-Hafidz. 2008. Bimbingan Praktis menghafal Al-qur'an. Jakarta: Bumi Aksara.

Ardy Wiyani, Novan. 2013. Pendidikan Agama Islam Berbasis Pendidikan Karakter. Bandung: Alfabeta.

Bungin, Burhan. 2001. Metodologi Penelitian Kualitatif. Jakarta: Raja Grafindo Persada.

Dalyono. M. 2009. Psikologi Pedidikan, Jakarta: Rineka Cipta

Danim, Sudarwan. 2002. Menjadi Peneliti Kualitatif. Bandung: Pustaka Setia.

Desmita. 2015. Psikologi Perkembangan Peserta Didik: Panduan Bagi Orang Tua dan Guru Dalam Memahami Psikologi Anak Usia SD, SMP, SMA, Bandung. PT. Remaja Rosdakarya.

Uno, Hamzah B. 2013. Teori Motivasi dan Pengukuranya: Analisa di Bidang Pendidikan, Jakarta: Bumi Aksara.

Hidayat Arif Muhammad.1019.Hubungan Kebiasaan Membaca Al-quran dengan Pembentukan Karakter gama Islam Siswa KeLAS X MAN Model Medan. Studi Ilmu-Ilmu Al-quran dan Hadis. 18(2).

Kamus Besar Bahasa Indonesia Edisi Ketiga , (2003). Jakarta:Departemen Pendidikan Nasional Balai Pustaka.

Khodijah, Nyayu. 2014. Psikologi Pendidikan, Jakarta: rajawali Press.

Moleong, Lexy J. 2013. Metode Penelitian Kualitatif. Bandung: PT. Remaja Rosdakarya.

Nazir, Moh. 2005. Metode Penelitian. Jakarta: Ghalia Indonesia.

Peraturan Pemerintah No. 73 tahun 1991 Pasal 3Tentang Pendidikan Luar Sekolah.

Peraturan Pemerintah No. 55 tahun 2007 Pasal 1Tentang Pendidikan Agama dan Pendidikan Keagamdan.

Peraturan Pemerintah No. 55 tahun 2007 Pasal 21 Ayat 1 Tentang Pendidikan Agama dan Pendidikan Keagamdan.

Profil Rumah Tahfidz Bakti Ilahi (RTBI).

Rafiqah, Mar'atur. Pengaruh Motivasi Belajar Terhadap Prestasi Belajar. 29 Juli 2016. file:///C:/Users/USER/Downloads/1661-3490-1-PB\%20(1).pdf .

Sardiman A.M, 2014, Interaksi dan Motivasi Belajar Mengajar, Jakarta: rajawali Press.

Soemanto, Wasty. 2012. Psikologi Pendidikan : Landasan Kerja Pemimpin Pendidikan, Jakarta: Rineka Cipta.

Subagyo, Joko. 2006. Metode Penelitian dalam Teori dan Praktek. Jakarta: Rineka Cipta.

Subini, Nini. 2012. Psikologi Pembelajaran, Yogyakatra: Mentari Pustaka.

Sugiyono. 2006. Metode Penelitian Kualitatif, Kuantitatif, dan $R \& D$. Bandung: PT. Remaja Rosdakarya.

Sukring. 2013. Pendidik dan Peserta Didik dalam Pendidikan Islam, Yogyakarta: Graha Ilmu. 
Sunarto. 2013. Perkembangan Peserta Didik, Jakarta :Rineka Cipta

Syah, Muhibbin . 1997. Psikologi Pendidikan dengan Pendekatan Baru. Bandung. PT. Remaja Rosdakarya.

Undang-Undang RI No. 20 Tahun 2003 Pasal 1 Ayat 4. Tentang Sistem Pendidikan Nasional, Jakarta

Undang-Undang RI No. 20 Tahun 2003 Pasal 12. Tentang Sistem Pendidikan Nasional, Jakarta.

Winarno Surakhmad. 1980. Pengantar Penelitian Ilmiah (Dasar, Metode dan Tehnik). Bandung: Tarsito. 